\title{
UMA ANÁLISE CRÍTICA DA TELEOSEMÂNTICA INFORMACIONAL DE FRED DRETSKE
}

\author{
Karla Chediak ${ }^{1}$ \\ Universidade do Estado do Rio de Janeiro (UERJ) \\ (D) https://orcid.org/0000-0001-7891-7693
}

\section{RESUMO:}

Discuto, neste artigo, a proposta de uma teleosemântica informacional, tal como concebida por Fred Dretske. Sustento neste texto que, embora a teleosemântica informacional defronte-se com sérias dificuldades relativas à determinação dos conteúdos das crenças, ela oferece bons critérios para distinguir sistemas meramente informacionais de sistemas representacionais.

PALAVRAS-CHAVE: Dretske; Representação; Teleosemântica informacional; Crença.

\section{A CRITICAL ANALYSIS OF FRED DRETSKE'S INFORMATIONAL TELEOSEMANTICS}

\begin{abstract}
:
I discuss in this paper the proposal of informational teleosemantics, as it was conceived by Fred Dretske. I sustain that, although informational teleosemantics faces serious difficulties concerning determination of the content of beliefs, it provides good criteria to distinguish merely informational systems from representational systems.
\end{abstract}

KEY-WORDS: Dretske; Representation; Informational teleosemantics; Belief.

${ }_{1}$ Professora Associada do Departamento de Filosofia da Universidade do Estado do Rio de Janeiro (UERJ), Rio de Janeiro - Brasil. Pesquisadora CNPq. E-mail: kachediak@gmail.com

CHEDIAK, Karla. Uma análise crítica da teleosemântica informacional de Fred Dretske. Griot : Revista de

Filosofia, Amargosa/Bahia, v.16, n.2, p.1-10, dezembro/2017. 
Neste artigo, analiso a proposta de naturalização da cognição presente na teleosemântica informacional proposta por Fred Dretske. Procuro mostrar que a teleosemântica informacional oferece bons critérios tanto para caracterizar o que são sistemas informacionais naturais e sistemas representacionais em geral quanto para distinguir sistemas não cognitivos de sistemas cognitivos.

Eu defendo, a partir da proposta de Dretske, que o conceito de representação quando pensado segundo o ponto de vista da evolução biológica, portanto, quando naturalizado, pode ser usado para explicar algumas das atividades cognitivas presentes nos animais. No entanto, mostro também que a teleosemântica informacional não é adequada para lidar com sistemas representacionais complexos, como os que envolvem o uso de linguagem proposicional.

\section{Função e representação}

O conceito de representação é frequentemente empregado quando da explicação de fenômenos cognitivos, não sendo, contudo, totalmente claro em que consiste propriamente o representar. De modo geral, estados representacionais são pensados como possuidores da propriedade funcional de estar em lugar de alguma coisa outra que eles, quer dizer, estados representacionais possuem uma natureza intencional por serem sobre alguma coisa. Entretanto, essa caracterização é ampla demais para especificar o papel cognitivo das representações, devendo ser restringida de algum modo para poder dar conta das atividades cognitivas. Podemos, então, considerar que representações não apenas estão em lugar de alguma coisa, senão que, em acréscimo, elas também desempenham um papel causal na determinação das atividades do sistema ao qual elas pertencem. Embora seja mais específica que a anterior, essa condição ainda não é suficiente para explicar a atividade cognitiva. Um termostato de um aparelho de ar condicionado satisfaz, por exemplo, essa condição, não consistindo, porém, em um sistema cognitivo. É verdade que Dretske diz que coisas como termostatos e velocímetros podem desempenhar uma função representacional, mas eles não constituem sistemas representacionais naturais, pois, como artefatos, seus poderes representacionais derivam daqueles que os criaram ou utilizam. Esses poderes são, por assim dizer, derivados de agentes intencionais que são humanos e possuem mentes. Em função disso, eles não vêm a ser exatamente um tipo de sistema representacional que interesse nessa discussão, visto que ela concerne exclusivamente a sistemas representacionais naturais.

Outras condições, no entanto, podem ser introduzidas para tornar mais estrita nossa concepção de representação. Pode ser dito que um estado é representacional quando ele está presente em um sistema e desempenha um determinado papel funcional em virtude do qual ele guia o comportamento desse sistema. Mas mesmo essa concepção não seria ainda satisfatória, pois plantas podem satisfazer essa condição e, creio, bem poucos filósofos, se é que há algum, estariam dispostos a sustentar que elas possuem atividade cognitiva. Consideremos, por exemplo, o caso do fototropismo encontrável em certos vegetais. $O$ fototropismo é causado pela ação de um hormônio - a auxina - produzido nas terminações das hastes e raízes. A ação desse hormônio conduz a um alongamento das células no lado 
da planta que permanece no escuro, onde há uma maior concentração do hormônio e, por isso, a planta se curva para o lado de onde vem a luz.

De fato, o uso por demais abrangente do conceito de representação levou alguns filósofos a crer que o projeto de naturalização da representação estava sofrendo de um mal que podemos chamar de "pan-representacionalismo". Para lidar com essa dificuldade, é necessário estabelecer um critério que distinga entre os sistemas que podem ser descritos em termos puramente mecânicos e os sistemas que são sistemas representacionais reais. $O$ problema aparece quando se considera que "qualquer dispositivo ou sistema mecânico que use estruturas que supostamente desempenham o papel funcional quando, e somente quando, certas condições são satisfeitas, são verdadeiramente sistemas representacionais." (RAMSEY, 2007, p.145)

Penso que Ramsey tem razão ao levantar o problema de um uso demasiadamente amplo do conceito de representação e concordo que temos de introduzir um critério para distinguir entre uma representação e uma estrutura funcional no interior de sistema mecânico. No entanto, é também possível defender uma compreensão mais ampla do conceito de representação, desde que se estabeleçam distinções entre diferentes tipos de representação, como o faz Dretske, em Naturalizing the mind. Além disso, as dificuldades de conceituar sobre os diferentes níveis de cognição se apresentam para qualquer abordagem teórica.

O conceito de função por si só já introduz uma primeira e importante separação entre uma estrutura funcional e uma puramente mecânica, pois as estruturas funcionais não são satisfatoriamente explicadas por descrições mecânicas. Não é a mesma coisa dizer que a clorofila tem a função de realizar a fotossíntese e dizer que a clorofila realiza a fotossíntese por meio de tal e tal mecanismo. Explicações funcionais não consistem em descrições puramente funcionais de processos mecânicos. Essas explicações devem prover não apenas um esclarecimento de qual é o papel que a estrutura representacional está desempenhando no interior do sistema ao qual ela pertence, mas devem também explicar por que há uma tal estrutura desempenhando um certo papel funcional, e permitir a distinção entre funcionamento normal e um mau funcionamento. Dito de outra maneira, a explicação funcional possui um caráter normativo. Ela ajuda a explicar o comportamento de um sistema, órgão ou traço biológico, estabelecendo as condições normais de funcionamento. Diz-se, por exemplo, que a função do coração é bombear sangue pelo corpo, mas um coração defeituoso possuiria essa função ainda que não pudesse realizá-la. Esse fato se deixa explicar através do apelo ao caráter normativo do conceito de função. Uma estrutura funcional é requerida ou selecionada a realizar sua função graças ao papel que ela desempenha no sistema ao qual pertence.

De fato, como vimos acima, para que algo seja uma representação é geralmente requerido que ele possa ter a função de estar no lugar de uma característica do meio ambiente. Essa é uma caracterização importante, mas, como John Haugeland (1991) já o observou, ela não é suficiente. Ele propôs uma restrição adicional que diz que é também necessário que a representação possa estar presente quando aquela característica está ausente. Somente nesse caso a representação está efetivamente no lugar de algo, guiando o sistema e respondendo pelo seu comportamento. De outro modo, a representação poderia não responder realmente 
pela produção do comportamento, pois ele seria guiado diretamente pelo meio circundante (HAUGELAND, 1991, p. 62).

Essa exigência expressa a ideia geral de que para algo ser uma representação, ele necessita, em adição às restrições mencionadas acima, ter alguma independência daquilo que ele representa. $O$ que é requerido é que a estrutura representacional, e, então seu conteúdo, realmente responda pelo efeito no output comportamental.

\section{Teleosemântica informacional e representação}

De acordo com Dretske, uma representação é uma estrutura física que está associada a algum aspecto do ambiente circundante com o qual ela covaria. Ela desempenha uma função no sistema ao qual pertence e tem um papel importante para os organismos por ajudá-los a lidar com seu ambiente circundante e guiar seu comportamento. Considerando que a função determina ao menos parcialmente o conteúdo de uma representação cognitiva, podemos dizer que essas representações são estados neurofisiológicos que veiculam certo conteúdo. Representações, porque possuem conteúdo, estão sujeitas à correção. Isso significa que elas podem representar de maneira incorreta [misrepresent] e nós podemos apelar precisamente a esse papel funcional para explicar a representação incorreta[misrepresentation]. ${ }^{2}$

A habilidade para representar foi gerada durante o processo de evolução de forma a permitir aos animais explorar ou manipular a informação disponível no meio no qual eles vivem e que é importante para sua sobrevivência e reprodução. De fato, há um relativo consenso de que habilidades cognitivas dos seres vivos são fruto do processo evolucionário, embora não haja consenso acerca de como elas evoluíram.

O conceito de informação utilizado por Dretske é compreendido de uma maneira naturalizada. As relações informacionais são pensadas como relações entre eventos ou estados do mundo, sendo, por isso, objetivas. De acordo com isso, as relações informacionais tornam-se cognitivas quando usadas ou operadas por organismos. Como Mark Rowlands assinala, esse é um aspecto importante do conceito de informação usado pela semântica informacional: "a informação é compreendida como estando objetivamente presente no meio ambiente independentemente dos estados representacionais de qualquer sujeito. De fato, a informação está objetivamente presente no meio ambiente mesmo se não houver sujeitos dos estados representacionais." (ROWLANDS, 1999, p.212). Relações

\footnotetext{
${ }^{2} \mathrm{O}$ fato de que algumas atividades cognitivas são representacionais não significa que todas tenham de ser pensadas como tal. Experimentos em Inteligência Artificial parecem mostrar que é possível produzir comportamentos sem o uso de representação. A habilidade de orientação e localização em robôs, por exemplo, pode ser alcançada sem representações. Além do mais, aqueles que favorecem uma abordagem dinâmica da cognição não concordam que seja necessário usar o conceito de representação para explicar o fenômeno cognitivo. Eles advogam o uso de outros conceitos tais como os de atratores e forças especiais, que não poderiam ser reduzidos a conceitos como crenças, desejos,etc. Entretanto, ainda que não seja necessário supor que todos os fenômeno cognitivos devam ser analisados apelando-se ao conceito da representação; como o esclarece o filósofo Andy Clark, os dois modelos principais que buscam explicar a cognição atribuem um papel importante para as estruturas representacionais: "connectionists and classicists (e.g., SMOLENSKY, 1988, FODOR \& PYLYSHYN, 1988) had at least this much in common: both camps held firm to the foundational role of the notion of internal representation in explaining intelligent behavior" (CLARK, 1994, p.403).
}

CHEDIAK, Karla. Uma análise crítica da teleosemântica informacional de Fred Dretske. Griot : Revista de Filosofia, Amargosa/Bahia, v.16, n.2, p.1-10, dezembro/2017. 
informacionais são, então, pré-cognitivas. Isso significa que não há informação incorreta [misinformation]. Um signo não pode veicular a informação de que $p$ a não ser que $p$ seja o caso. A informação não é nada mais do que relações de covariação entre estados de coisas que podem ser exploradas por animais. Essas relações informacionais se tornam representacionais, adquirindo conteúdo semântico e a possibilidade de representarem incorretamente - isto é, de representar $P$ quando $P$ não é o caso - ao serem usadas por algum organismo. Assim, a habilidade de representar, pelo menos para as formas mais simples de cognição, está originalmente associada à ação do indivíduo no meio-ambiente. Portanto, não se pode compreender o que um organismo é capaz de representar sem considerar o modo como ele interage com seu mundo. A compreensão de que a informação não está sujeita à correção é necessária se consideramos que a semântica informacional consiste em uma proposta de naturalização da representação. Para evitar qualquer circularidade, o conceito de informação não pode ele mesmo depender de nenhuma estrutura semântica.

Em seu Knowledge and the flow of information, Fred Dretske fornece uma definição do que significa informação: "um sinal $\mathrm{r}$ carrega a informação de que $s$ é $F$ $=$ a probabilidade condicional de $s$ sendo $f$, dado $r$ (e $k$ ), é 1 (mas, dado apenas $k$, é menor do que 1)" (DRETSKE, 1982, p. 65). De acordo com essa definição, se a probabilidade condicional do sinal que carrega a informação " $s$ é $F$ " é igual a 1, segue-se necessariamente que: (1) a equivocação do sinal é zero, e (2) $s$ é $F$. Mais ainda, $s$ irá carregar também toda a informação que está analiticamente e nomicamente abrigada em $F$. A variável $K$ refere-se à informação obtida anteriormente pelo receptor e que faz diferença no resultado final. $K$ não poderia, sob risco de circularidade, ser considerado um conhecimento ou uma representação.

A informação está baseada, então, em regularidades nômicas das quais ela depende. ${ }^{3}$ Elas estão fixadas em estruturas neurofisiológicas que adquirem poderes causais porque elas carregam conteúdo informacional que afetam o comportamento do animal. Assim, de acordo com a semântica informacional desenvolvida por Dretske, o conteúdo de uma representação é determinado pela informação que ela carrega.

\section{Crítica à teleosemântica informacional}

Há alguns problemas com essa caracterização de informação e é possivel perguntar se ela é a melhor concepção de informação a ser usada para explicar a representação e se o conceito de informação é realmente a mais apropriada para determinar a natureza da cognição.

Um problema com a teleosemântica informacional diz respeito à exigência de que a probabilidade condicional do signo que carrega a informação seja igual a 1. Isso significa que não há erro nas relações informacionais. Considerando que, para Dretske, só há representação cognitiva propriamente dita nos casos de experiência

\footnotetext{
${ }^{3}$ A informação está usualmente acompanhada por relações causais e depende delas, mas informações relacionais não são relações causais. É possível ter relações causais entre dois eventos e não ter nenhuma informação em função de equivocidade. É também possível ter relação informacional entre dois eventos e não ter relações causais entre eles. Nesse caso, a relação informacional é suportada pela relação causal que tem de existir entre cada evento e um terceiro. Ver DRETSKE, 1982.
}

CHEDIAK, Karla. Uma análise crítica da teleosemântica informacional de Fred Dretske. Griot : Revista de Filosofia, Amargosa/Bahia, v.16, n.2, p.1-10, dezembro/2017. 
individual, de aprendizado, a consequência que se segue é a necessidade de se distinguir entre um período de aprendizagem, durante o qual somente há somente relação informacional e o erro não é possível, e o período subsequente, no qual representações (tokens) são formadas, podendo haver representações incorretas (misrepresentations). O problema é que não parece haver base empírica para sustentar uma tal distinção entre um pré-aprendizado e um pós-aprendizado.

Uma forma de superar essa dificuldade é reconhecer que a exigência de que haja regularidade nômica nas relações informacionais é excessiva. Ruth Millikan corretamente observa que essa condição não é facilmente satisfeita quando consideramos a formação de representações em animais; provavelmente ela não pode nunca ser satisfeita (MILLIKAN, 2006, p.32).

O ponto importante é perguntar se é necessário defender um conceito tão forte de informação para sustentar uma perspectiva informacional de representação. Eu penso que não o é. De fato, mesmo Dretske coloca essa ideia de lado. Ao menos, um de seus exemplos principais em Explaining behavior não satisfaz essa condição. De acordo com ele, quando alguém ouve uma campainha tocando, ele acredita que uma pessoa está tocando a campainha. Não há lei natural que garanta que somente pessoas toquem campainhas. É verdade que, em geral, são pessoas que tocam as campainhas, mas nada impede que outros animais aprendam a fazer isso (DRETSKE, 1995a, p. 57).

Millikan, a meu ver, tem razão quando se propõe a lidar com o conceito de informação natural de uma maneira menos estrita do que a de Dretske. Os sinais que carregam informações relevantes para os organismos não precisam possuir um caráter absoluto; eles necessitam apenas carregar informações localmente confiáveis. Ela defende que as informações das quais os sistemas cognitivos dos animais dependem são aquelas disponíveis em seu meio ambiente, assentando-se em uma estatística local, e não em uma lei natural. $O$ tipo de informação que os organismos usam em sua interação com o meio ambiente não satisfaz, de nenhuma maneira, o critério que Dretske apresenta em Knowledge and the flow of information, pois essas são apenas informações obtidas a partir de frequências estatísticas mais ou menos estáveis, relativas a um domínio espacio-temporal específico. A dependência, nesse caso, não está fundada em uma lei natural, mas também não é uma mera coincidência. Como Millikan observa, deve haver um meio termo entre as frequências estatísticas resultantes de uma feliz coincidência, por um lado, e a necessidade da lei natural, por outro (ver MILLIKAN, 2000, p. 234). Consequentemente, não necessitamos de maneira nenhuma endossar a distinção entre o período de aprendizado e o período subsequente.

De acordo com a teleosemântica informacional, meros processadores de informação e sistemas representacionais, com conteúdo semântico, distinguem-se, porque somente sistemas representacionais estão sujeitos à correção. Essa distinção, porém, nada diz sobre a distinção entre sistemas representacionais cognitivos e não cognitivos.

De certa maneira, a exigência apresentada por Haugeland de que para algo ser, cognitivamente falando, uma representação, ele tem apresentar alguma independência daquilo que ela representa, aparece também na semântica informacional proposta por Dretske. De acordo com esse autor, para que uma 
estrutura física seja representacional é necessário individuar seu conteúdo independentemente de seu êxito em carregar a informação (DRETSKE, 1982, p. 192). Para ele, a habilidade de formar estruturas representacionais cognitivas só estaria presente nos animais que são capazes de interagir com o ambiente circundante através da experiência individual, por meio de aprendizado. As estruturas representacionais que são formadas através de um processo filogenético, por não dependerem de aprendizado individual, não satisfazem essas condição. Por isso, elas não desempenham realmente um papel cognitivo, pois não é possível atribuir ao seu conteúdo a independência necessária para ser uma representação.

Esse critério visa estabelecer a distinção entre representações não cognitivas e representações cognitivas genuínas. Porém, ele sozinho também não é suficiente. Pode-se considerar que um signo que tem a função de carregar uma informação, carrega também toda a informação que se encontra nomologica e logicamente nele contida. Assim, se $r$ carrega a informação de que $s$ é $F$, então $r$ carrega a informação de que $s$ é $G$, caso tal informação esteja nomologicamente ou logicamente contida em $s$ sendo $F$. Contudo, essa consequência não é compatível com a caracterização de representação que Dretske defende. Esse fato introduziria uma indeterminação na especificação na informação que seria função da representação informar.

A solução de Dretske para essa dificuldade é sustentar que a representação é indissociável da ação que a requereu. Ela tem a função de carregar informação ou indicar $F$ (um estado de coisas, objetos ou propriedades) quando é requisitada por uma ação ou uso porque ela indica ou informa $F$. Ter a função de carregar informação não é apenas carregar informação; ter essa função pressupõe que uma relação de covariação tenha sido estabelecida entre alguma estrutura física interna, neurológia e corporal, e algum aspecto do mundo devido à informação específica que a estrutura carrega. Essa relação está baseada, primeiramente, na associação entre a representação e o que determina seu conteúdo, a informação, e, em segundo lugar, na relação entre a representação e a ação. $O$ papel causal da representação estaria assegurado porque a estrutura interna que causa a ação seria requisitada graças a seu conteúdo informacional.

Isso é suficiente, segundo Dretske, para especificar a informação que está sendo veiculada. A estrutura $r$ carrega a informação de que $s$ é $F$, e também carrega a informação de que $s$ é $G$ e $H$, uma vez que ser $G$ e ser $H$ estão nomologicamente incorporados em $s$ ser $F$. Contudo, ela apenas representa que $s$ é $F$, e não que $r$ é $G$ ou que $s$ é $H$, pois a estrutura $r$ foi requisitada em função de seu conteúdo informacional de $s$ ser $F$, e não por causa do conteúdo de $s$ ser $G$ ou $H$. Pode-se supor, que se $s$ não fosse $F$, fosse apenas $G$ ou $H$, ele não teria papel representacional. $O$ estado $r$ não relacionaria o estado do ambiente e a ação do indivíduo. Isso significa que uma vez estabelecida a função de informar é possível determinar o conteúdo da representação como sendo único.

Dretske fornece ainda um outro argumento para caracterizar os sistemas representacionais genuinamente cognitivos. Esse argumento baseia-se na autonomia ou independência do conteúdo representacional relativamente a seu veículo. Sistemas que podem extrair informação de diferentes fontes de sinais. Alguém pode saber, por exemplo, que uma pessoa se casou lendo a notícia em um jornal, ou a ouvindo no rádio, vendo na TV ou presenciando pessoalmente a própria cerimônia de 
casamento. Sem embargo, poderíamos perguntar se essa solução é capaz de solucionar o problema da diferença entre um sistema representacional e um sistema representacional cognitivo. Esse argumento introduz a flexibilidade necessária para que se possa recorrer ao conteúdo de forma relativamente independente do veículo de conteúdo, pois ter veículos diferentes carregando o mesmo conteúdo, faz com que o conteúdo representacional responda pela ação que dele resulta e não o veículo.

Ainda que a solução de Dretske para o problema de como diferenciar sistemas puramente informacionais dos sistemas de representação, e diferenciar sistemas representacionais cognitivos de outros sistemas representacionais apoiado nos conceitos de informação, de função, de correção e de flexibilidade e de ação seja satisfatória, há uma última dificuldade que sua semântica precisa tratar, a distinção entre representação e crença.

\section{Representações e crenças}

Alguns filósofos, como Brian McLaughlin, têm argumentado que há um problema com a teoria semântica informacional proposta por Dretske, caso ela pretenda realmente explicar o conteúdo das crenças com base no conceito de informação. Como explicar, por exemplo, a diferença entre as crenças "há água" e "há $\mathrm{H}_{2} \mathrm{O}$ "? " Este problema é levantado por McLaughlin, que afirma: "é difícil ver como isso poderia ocorrer, por exemplo, como a condição de água estar presente poderia ser $\neq$ da condição de $\mathrm{H}_{2} \mathrm{O}$ estar presente" (McLAUGHLIN, 1991, p. 165). Para ele, a história relatada acerca do aprendizado ou da aquisição da função da informação não fornece meios para distinguir a função natural de que a água está presente da função natural de informar que $\mathrm{H}_{2} \mathrm{O}$ está presente. $\mathrm{O}$ aprendizado não seria sensível a essa diferença. É que crenças individuam de um modo mais fino do que meras informações o fazem, uma vez que, ao contrário dessas, elas são opacas. Quer dizer, uma crença pode representar que $s$ é $F$ e não representar que $s$ é $G$ ainda que haja uma relação nomológica (lei natural) ligando $F$ e $G$. Por exemplo, um sinal que carrega a informação de que a água está congelando carregará também a informação de que a água está se expandindo, uma vez que há uma lei natural que diz que a água se expande ao congelar. Entretanto, alguém pode muito bem acreditar que a água está congelando sem acreditar que a água esteja se expandindo.

McLaughlin crê que a introdução do conceito de função não é suficiente para explicar a distinção entre representação informacional e crença. Devido a isso, o conteúdo da representação informacional não pode determinar o conteúdo de uma crença. Ele não é suficiente, pelo menos não por si mesmo, para determinar o conteúdo das crenças, posto que o critério de ter a função de informar, ou de ser utilizado para informar, não parece ser suficiente para distinguir o conteúdo das crenças dos termos co-referenciais. Isto significa que não distingue entre ter a função de informar água e ter a função de informar $\mathrm{H}_{2} \mathrm{O}$, considerando que a água é $\mathrm{H}_{2} \mathrm{O}$ e que alguém pode crer que $s$ é água sem crer que $s$ é $\mathrm{H}_{2} \mathrm{O}$.

\footnotetext{
${ }^{4} \mathrm{O}$ problema com os termos correferenciais é conhecido como Frege's puzzle. Ele consiste no problema de como distinguir crenças que se formulam com termos que possuem o mesmo referente. McLaughlin usa este problema para argumentar que a informação não pode determinar o conteúdo das crenças.
}

CHEDIAK, Karla. Uma análise crítica da teleosemântica informacional de Fred Dretske. Griot : Revista de Filosofia, Amargosa/Bahia, v.16, n.2, p.1-10, dezembro/2017. 
Creio que a semântica informacional de Dretske não oferece um tratamento adeuqado para esses casos. No entanto, é possível se considerar que nem toda representação é uma crença. As crenças estão relacionadas com atitudes proposicionais e, consequentemente, sua posse pressupõe a posse de uma linguagem proposicional. Sua natureza discursiva implica algumas características especiais, tais como ser de composição estruturada, sistemática e produtiva, tal como bem o mostrou Jerry Fodor. Se há representações não linguísticas - e eu creio que as há - a semântica informacional pode ser apropriada para dar conta delas, ainda que não o seja no caso das crenças, uma vez que a determinação do conteúdo das crenças, mesmo as mais simples, não pode se dar com base unicamente no conteúdo informacional por elas veiculado. A distinção entre crenças que envolvem termos coextensionais, por exemplo, estaria baseada em uma característica específica das crenças composicionais.

A distinção que Dretske estabelece em seu livro Knowledge and the flow of information entre conteúdo semântico e estrutura cognitiva não fornece uma solução para a dificuldade. No caso da água e do composto $\mathrm{H}_{2} \mathrm{O}$, haveria o mesmo conteúdo semântico, porém diferentes estruturas cognitivas. A estrutura cognitiva estaria relacionada ao modo pelo qual o conteúdo semântico é codificado e conceitualizado. Dretske observa que duas crenças podem ter o mesmo conteúdo semântico e diferir apenas em função da maneira pela qual codificam tal conteúdo (DRETSKE, 1982, p.218). De acordo com essa perspectiva, o conteúdo semântico de "s é água" e de "s é $\mathrm{H}_{2} \mathrm{O}^{\prime}$ é o mesmo, e é a informação que essas crenças levam relativamente a $s$ que é codificado como água ou como $\mathrm{H}_{2} \mathrm{O}$. Consequentemente, uma crença não é individualizada apenas pelo seu conteúdo semântico, mas também pela maneira pela qual está estruturada conceitualmente.

Quando consideramos unicamente representações mais simples, que não são linguísticas, o problema com os termos correferenciais simplesmente desaparece, uma vez que tais representações não possuem uma estrutura composta. Nesse caso, os termos correferenciais que expressam as representações mais simples teriam o mesmo conteúdo semântico e não possuiriam estrutura cognitiva e isso significa que seria exatamente o mesmo dizer que um animal sem linguagem representa água ou $\mathrm{H}_{2} \mathrm{O}$. E é por isso que a teleosemântica informacional proposta por Dretske não é adequada pata tratar da cognição que depende do uso da linguagem proposicional. 


\section{Referências bibliográficas:}

CLARK, A. (1994) “Doing without Representing?”, Synthese, 101(3), 401-431.

DRETSKE, F. (1995a) Explaining behavior. Reasons in a world of causes, Cambridge, MIT Press.

(1982) Knowledge and the flow of information, Cambridge, MIT Press.

(1995b) Naturalizing the mind, Cambridge, MIT Press.

HAUGELAND, J. (1991) "Representational Genera", Ramsey, W. et alli (ed.), Philosophy and connectionist theory, Hillsdale, Lawrence Erlbaum Publ., 61-89.

MCLAUGHLIN, B. (1991) Dretske and his critics, Cambridge, Blackwell.

MILLIKAN, R. (2000) On clear and confused ideas. An essay about substance concepts, Cambridge, Cambridge Univ. Press. (2006), Varieties of meaning, Cambridge, MIT Press.

NEANDER, K. (2004) Teleological Theories of Mental Content, http://plato.stanford.edu/.

RAMSEY, W. (2007) Representation reconsidered, Cambridge, Cambridge University Press.

ROWLANDS, M. (2004) The body in mind. Cambridge, Cambridge Univ. Press.

Autor(a) para correspondência: Karla Chediak, Universidade do Estado do Rio de Janeiro, R. São Francisco Xavier, 524, Maracanã, CEP 20550-900, Rio de Janeiro - RJ, Brasil. kachediak@gmail.com 